\title{
A Computer-Controlled Environmental Chamber for the Study of Aerial Fungal Spore Release
}

\author{
T. R. Gottwald, T. M. Trocine, and L. W. Timmer
}

First author: U.S. Department of Agriculture, Agricultural Research Service, U.S. Horticultural Research Laboratory, Orlando, FL 32803; second author: DPT 140 Candace Dr., Maitland, FL 32751; and third author: Citrus Research and Education Center, University of Florida, Institute of Food and Agriculture, Lake Alfred 33850.

Accepted for publication 20 July 1997.

\section{ABSTRACT}

Gottwald, T. R., Trocine, T. M., and Timmer, L. W. 1997. A computercontrolled environmental chamber for the study of aerial fungal spore release. Phytopathology 87:1078-1084.

An environmental chamber was designed to study aerial release of spores of ascomycetes and hyphomycetes, based on a device developed by C. M. Leach. Relative humidity $(\mathrm{RH})$, temperature, red $(660 \mathrm{~nm})$ and infrared $(880 \mathrm{~nm})$ light, leaf wetness, wind speed, vibration, and rain events are controlled and monitored within the chamber via an RTCHC11 real-time controller and data-acquisition system. A BASIC11 computer program is uploaded to and controls the system. The program requests values for environmental parameters that change through time according to user specifications. The controller interacts with a stepper motor, solenoids, and relay switches via a feedback system based on data received from solid-state $\mathrm{RH}$, temperature, and leaf-wetness sensors. The data-acquisition system records environmental data from the chamber in RAM (random access memory) that can be downloaded to a personal computer for correlation with spore-release data. Spores released from fungal specimens on plant tissues and cultures placed in the chamber and subjected to the desired environmental conditions are collected on a continuous volumetric spore trap at an exhaust port from the chamber. The performance of the device was examined by measuring spore release of Mycosphaerella citri, Alternaria solani, and Venturia inaequalis under various environmental conditions.

Additional keywords: apple scab, citrus greasy spot, early blight of tomato and pepper.
Spore and sporangium release of fungal pathogens has long been recognized as an important aspect of the epidemiology of fungal diseases caused by some ascomycete, basidiomycete, oomycete, and hyphomycete pathogens $(2,14,15,25)$. Knowledge of the environmental triggers for spore release potentially could lead to improved disease control measures by horticulturally modifying the environment to limit spore release when plants are most susceptible to infection and stimulating spore release during periods when environmental conditions are least favorable for infection. The intention is to deplete spore loads during periods when plants are least susceptible or when conditions are unfavorable for infection. Spore release is augmented or stimulated by rainfall for several pathogens $(3,5,11,16,23,24,27-29)$. The effects of free moisture on plant surfaces, shifts in relative humidity $(\mathrm{RH})$, vibration, wind, and red and infrared wavelengths of light have been studied and are related to spore and sporangium release for several fungi $(1,4,5,8-10,12,13,17,19-22,26,29)$. An apparatus for precise control of RH, temperature, airflow, and light was developed by C. M. Leach (18). Similar devices based on the same concept have been used to study spore release from several plant and insect pathogens $(1,6,8-10,17,19-21)$. The objective of the current study was to develop and test a new apparatus for studying spore release based on the concepts of the Leach device but with a program-

Corresponding author: T. R. Gottwald, E-mail address: gott@magicnet.net

Mention of a trademark, warranty, proprietary product, or vendor does not constitute a guarantee by the U.S. Department of Agriculture and does not imply its approval to the exclusion of other products or vendors that may also be suitable.

Publication no. P-1997-0825-03R

This article is in the public domain and not copyrightable. It may be freely reprinted with customary crediting of the source. The American Phytopathological Society, 1997. mable computer interface for conducting unattended, long-term experiments with multiple environmental parameter changes, a dataacquisition system, solid-state electronic probes, and the ability to simulate rain.

\section{MATERIALS AND METHODS}

The computer-controlled environmental chamber (CCEC) consists of three main parts: the atmosphere preconditioning system, the environmental chamber, with associated probes and rain tower, and the computerized environmental controller/data-acquisition system.

Preconditioning the atmosphere. Air enters the system from a compressed air source in the laboratory at $517 \mathrm{kPa} \mathrm{m}^{-2}$ and immediately splits into two lines (Fig. 1). Both lines pass through pressure regulators with oil water traps and pressure gauges (Speedaire model 4Z029; Dayton Electric Manufacturing Co., Chicago), each balanced with the downstream system at $103 \mathrm{kPa} \mathrm{m}^{-2}$. The output of the first line passes through a series of three dryers, $6 \mathrm{~cm}$ diameter $\times 25 \mathrm{~cm}$ long, containing indicating silica gel that can be reused by drying. The series of dryers reduces the RH to $\approx 15 \%$. The second line passes through a series of six humidifiers, each consisting of a glass jar containing an oil filter wick and $\approx 100 \mathrm{ml}$ of distilled water. The system of humidifiers is capable of raising the RH to $\approx 95 \%$ (18). Each humidifier has a sealable suction fitting (B\&B Specialties Inc., Granger, IN) through which the water level can be recharged.

The dried and humidified air lines rejoin at a mixer valve (model 09975B; Price Pfister, Pacoima, CA) controlled by a stepper motor (Vexta model PH266M-E1.2(B); Oriental Motor USA, Torrance, CA) whose controller (model SDM-7, anti-resonance, fullhalf step; New England Affiliated Technologies, Lawrence, MA) is under feedback RH control (described below; Fig. 1). The air, thus, can be preconditioned to any setting in the range of 15 to $95 \% \mathrm{RH}$. If saturated or nearly saturated air, i.e., 95 to $100 \% \mathrm{RH}$, 
is required, air is diverted by a $24-\mathrm{V} \mathrm{AC}$, three-way solenoid valve (model 3A426; Dayton Electric) directly from the six humidifiers and bypasses the mixer valve. Humidified/dried air passes through a coil of 6-mm-diameter copper tubing housed within a heated/refrigerated water bath (KoolMate thermoelectric cooler and warmer, model 12; Igloo Products Corp., Houston). Air temperature within the final chamber is controlled by the water bath. Water bath temperature is adjusted by switching the heating or cooling cycles of the water bath by reversing the electrical polarity to the $12-\mathrm{V}$ power supply. The conditioned air passes through a condenser, constructed of 5-cm-diameter (2-in.) PVC pipe and cap fittings, to eliminate free moisture. Sensors located at the bottom of the condenser detect the presence of water by electrical conductivity and cause a 24-V AC, solenoid valve (model 1A575; Dayton Electric) to open and discharge the free water from the system. The air passes through a flow meter (model GR150; Key Instruments, Trevose, PA) to adjust the air flow within the specimen chamber, through a series of open-cell foam-rubber diffusers, and into the specimen chamber.

Environmental specimen chamber. The environmental chamber is constructed of a 10-cm-diameter (4-in.) PVC “T" fitting (Fig. 1). The air flows into the chamber through a series of PVC pipe reducers that hold the air diffusers at one end of the long axis of the PVC T. The plant tissue specimen is held between two $1.6 \times$ $10 \times 20$-mm Fiberglas frames on which a grid of $0.45-\mathrm{kg}$ (1-lb) test monofilament fishing line is strung. The frames slide into slotted polyethylene rails attached to the inside side walls of the long axis of the PVC T. Two temperature sensors (model AD590LH; Analog Devices, Norwood, MA) and two solid-state capacitive RH sensors (series 691; Phillips Components, Mineral Wells, TX) are located on the roof of the environmental chamber-one of each kind at each end of the chamber. Two banks of high-intensity light-emitting diodes (LEDs) also are located on the roof of the chamber. Each light bank consists of six 1.82-V, 20-mA LEDs (model 276086, high-intensity red LED; Radio Shack Div., Tandy Corp., Fort Worth, TX) that emit 6,000-mcd red radiation at 660 $\mathrm{nm}$ and nine 1.82-V, 20-mA LEDs (model 276145, high-intensity infrared LED; Radio Shack) that emit 2,000-mcd infrared radiation at $880 \mathrm{~nm}$ onto the specimen without causing any perceptible increase in temperature within the chamber. The combined peak output from the LED light banks at the specimen level for red and infrared radiation was $15.2 \mu \mathrm{W} \mathrm{cm}{ }^{-2}$ at $650 \mathrm{~nm}$ and $3.99 \mu \mathrm{W} \mathrm{cm} \mathrm{cm}^{-2}$ at $890 \mathrm{~nm}$, respectively, measured with a multispectral radiometer (Isco, model SR; Instrumentation Specialties Co., Lincoln, NE). A surface-wetness impedance sensor, consisting of a $1.0 \times 30 \times 20$ $\mathrm{mm}$, flat-plate, copper-clad printed circuit board coated with two layers of latex-base porous paint, is located just under the specimen holder in the center of the environmental chamber to detect the presence and duration of free moisture (7). A portion of the side of the chamber was removed and replaced with Plexiglas to act as a window to allow viewing of the specimen, lights, rain, and probes inside.

A rain tower is attached to the environmental chamber to simulate rain on demand during experiments (Fig. 1). The rain tower consists of a 76-cm-high section of 10-cm-diameter PVC connected to the side arm of the PVC T, terminated by a threaded 10-cm-diameter PVC cleanout fitting. The cleanout plug holds a polyethylene atomizer that is connected via $4.8-\mathrm{mm}$-diameter ( $3 / 16$-in.) polyethylene tubing to a solenoid valve on the outside of the rain tower after passing through an adjustable flow meter to adjust the intensity of rain. The atomizer is activated by a $24-\mathrm{V}$ AC, solenoid valve (model 1A575; Dayton Electric) connected to a source of distilled water. The atomizer sprays downward onto a 1-mm mesh brass screen on which droplets form, and the droplets fall through the rain tower and onto the specimen, a distance of $69.8 \mathrm{~cm}$, simulating rain. The brass screen can be removed if a gentle mist directly from the atomizer is desired to settle onto the specimen. The rain tower is sealed to the environmental chamber

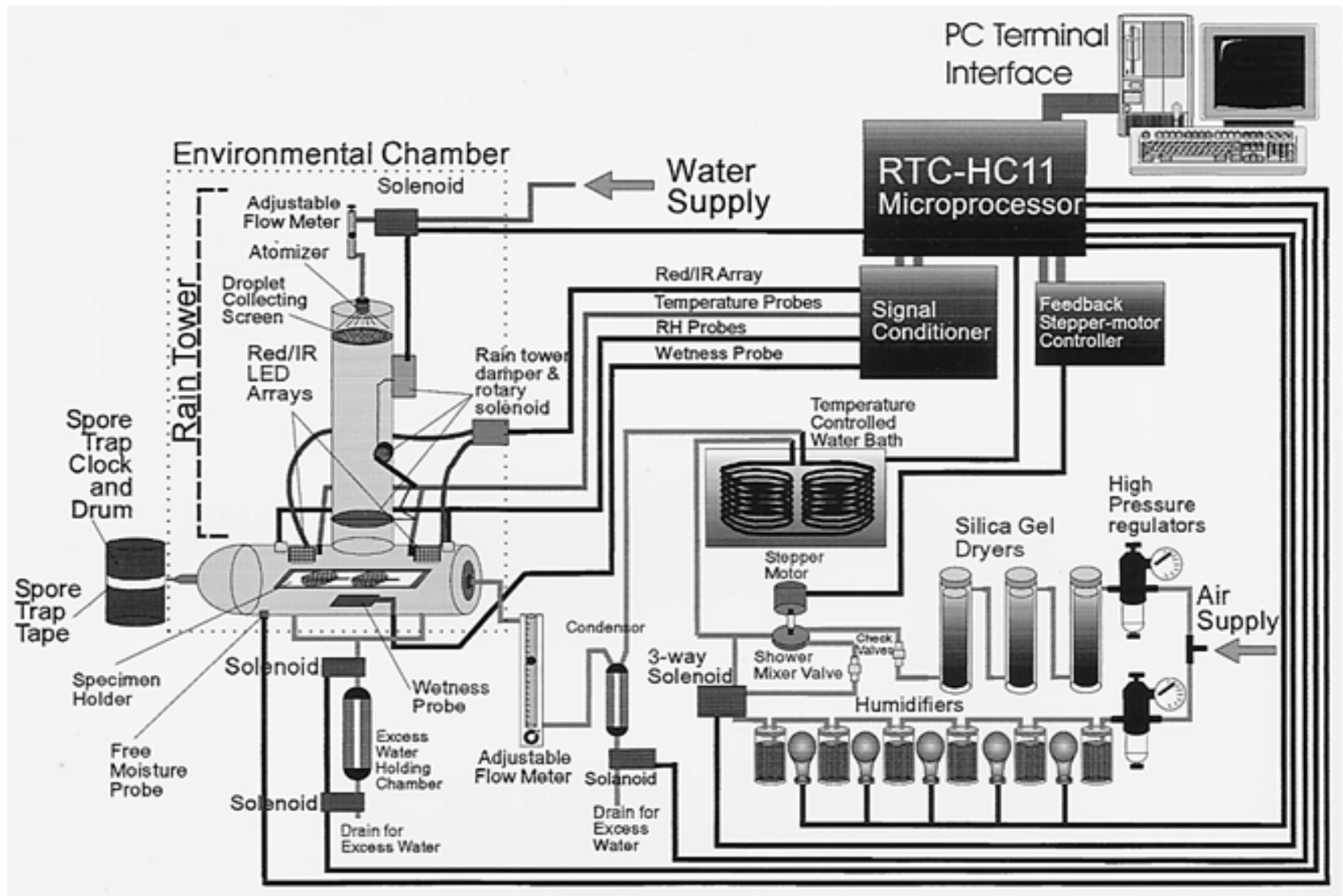

Fig. 1. Schematic diagram of the computer-controlled environmental chamber. Individual components and their functions are explained in text. 
with an O-ring gasket between and is held against the side arm of the PVC T by three thumbscrew latches around the circumference of the rain tower. An automatic damper, consisting of a flat 1-mmthick $\times 10$-cm-diameter Fiberglas plate, is located at the junction between the rain tower and the environmental chamber. The damper is connected to a lever system located outside the rain tower that is actuated by a $24-\mathrm{V}$ AC, rotary solenoid (model 81840; Ledex Inc., Vandalia, OH). The damper is opened automatically when rain is demanded by the computer program and closed when the rain event is completed. This seals off the rain tower from the rest of the environmental chamber to allow faster drying and more efficient air flow.

Water from simulated rain events collects in the bottom of the environmental chamber. Sensors located on the floor of the chamber, next to drain ports in the front and rear of the chamber, detect the presence of water by electrical conductivity and cause a $24-\mathrm{V}$ AC, solenoid valve (model 1A575; Dayton Electric) to open to discharge the free water from the system into an $\approx 1$-liter holding tank that is under the same atmospheric pressure as the environmental chamber. Water is discharged from this holding tank by opening a second drain at the bottom of the tank controlled by an identical solenoid valve programmed to operate only when the first solenoid valve is closed. In this way, pressure fluctuations and air flow in the environmental chamber are minimized.

The effect of vibration on spore release can be examined by actuating two 6-V DC, push-type solenoids (model 8611; Guardian Electric Manufacturing Co., Chicago) located on the outside of the environmental chamber at the level of the specimen holder that impact the chamber side with an energy potential of $\approx 0.11 \mathrm{~J}$.

The air exits the chamber through a $10-\mathrm{cm}$ polyethylene funnel, the tapered end of which extends through a 7.9-mm (5/16-in.) hole drilled in the center of a $10-\mathrm{cm}$ PVC cap fitting. The funnel is sealed to the inner cap wall with silicon caulk and acts as an inner tapered lining for better air flow. The cap fitting has an O-ring gasket and is held tight to the environmental chamber by a hinge on the top and thumbscrew latches at two other points around the circumference of the cap and chamber. The hinge allows access to the specimen holder and the inside of the environmental chamber by tilting up the cap. A copper exit nozzle with a $1 \times 10$-mm slitaperture is connected to the narrow end of the funnel via a $2-\mathrm{cm}-$ long segment of Tygon (Norton Plastic and Synthetics Inc., Akron, $\mathrm{OH}$ ) tubing (Fig. 1).

The spore trap is constructed from a mechanical chart drive and recording chart cylinder (model 14253; Belfort Instruments Co., Baltimore) and mounted on a rack-and-pinion track and shuttle for precision positioning (models M31,240 and M61,286; Edmund Scientific Co., Barrington, NJ) (Fig. 1). The spore-trapping surface is prepared by affixing a clear cellophane tape around the chart cylinder at the level of the exit nozzle, which is coated with a base mixture of $10 \%$ polyvinyl alcohol in distilled water and dried for 1 to $2 \mathrm{~h}$, followed by a second adhesive coat of petroleum jelly plus $10 \%$ paraffin thinned to a soft paste with toluene. The coated tape is heated on a hot plate until brush streaks in the trapping surface disappear, cooled, and mounted on the shuttle and positioned $\approx 1 \mathrm{~mm}$ from the slit-aperture of the exit nozzle. Spores released from the specimen in the environmental chamber pass through the slit-orifice and are impacted on the spore-trapping surface. The spore-trapping surface travels in front of the slitorifice at $\approx 11 \mathrm{~mm} \mathrm{~h}^{-1}$. This provides a resolution of 1.6-min collection time per microscope field width band across the slide when viewed at $400 \times$ and 1.3-min collection time per microscope field width band across the slide when viewed at $600 \times$. The exposed tapes are mounted in acid-fuchsin-lactophenol on a glass microscope slide. When spores are abundant, i.e., more than 500 spores per time increment, the number of spores per unit time is estimated from five representative microscope fields. When spores are less abundant, i.e., less than 500 spores per time increment, the spores within all microscope fields within the time increment are counted.
Computer hardware and electronics. The control and dataacquisition systems are designed around an inexpensive RTC-HC11 single-board, 8-bit computer/controller (Micromint Inc., Vernon, CT). The controller has asynchronous RS-232 serial communication capabilities to upload system and control programs written in BASIC11 (microcomputer control-oriented interpreter language; Micromint) and store them in a 64K SRAM (static random access memory) chip. Calibration variables and constants are stored in a 512K EPROM (erasable programmable read only memory) chip located on the Motorola (Phoenix) MC68HC11E9 microcontroller chip. The RTC-HC11 board also has a $32 \mathrm{~K}$ (or 64K) EPROM memory chip that holds the BASIC11 interpreter program. The BASIC11 program provides routines to upload the desired experimental parameters to RAM (random access memory) and download the environmental data acquired from the various probes during or after an experiment. The controller can store acquired data in RAM or transmit it as collected simultaneously to a personal computer (PC) through the RS-232 serial connection.

Signal conditioning for each of the environmental sensors required the design of new electronic circuitry and modification of circuitry suggested by the sensor manufacturers and included the integration of numerous electronic components and devices. Circuit schematics and component lists are available by request from T. R. Gottwald. All solenoid valves in the system are controlled via circuits that employ 5.0-V printed circuit board-mounted relays.

The RH-sensing circuit consists of two capacitive humidity sensors whose capacitance changes in response to changes in the $\mathrm{RH}$ within the environmental chamber. The circuit uses a switched capacitor circuit that alternately charges and discharges each capacitive sensor at a fixed frequency. The charge $(Q)$ on each sensor is directly proportional to the capacitance $(C)$ of the sensor, which in turn is directly proportional to the $\mathrm{RH}$, such that $Q=C V=R H \times V$, where the voltage $(V)$ is compared to a precision voltage reference (LT1009; Digikey Corp., Thief River Falls, MN), which provides a 2.5-V reference that is stable to within $15 \mathrm{ppm}$ over the entire operating range $\left(10\right.$ to $\left.40^{\circ} \mathrm{C}\right)$ of the chamber, and a $90 \%$ trim potentiometer is used to calibrate the circuit. A series capacitor is used to AC couple the sensors to the charge/discharge circuit to maintain a net $0 \mathrm{~V}$ across the sensor's terminals and, thus, prevent electrochemical degradation of the sensor's polymer-sensing element. The charge values of the two sensors are averaged and scaled by a final amplifier, and a 5\% adjustment potentiometer is used to provide an offset current in the summing junction to eliminate offset and leakage current errors from amplifiers and sensors. The resulting calibrated $\mathrm{RH}$ value is compared to that desired in the experimental design. A BASIC11 RH-control subroutine is used to drive the stepper-motor controller, which in turn adjusts the mixer valve to mix saturated and dry air, and, thus, provide the desired RH. A PID (proportional-integral-differential) antihysteresis algorithm is used in the humidity-compensation subroutine to damp out overcontrol effects. The compensation subroutine also controls the $100 \% \mathrm{RH}$ solenoid when RH levels of greater than $95 \%$ are desired.

The two semiconductor temperature sensors each produce a linear $( \pm 0.3 \%)$ output current of $1 \mu \mathrm{A} /{ }^{\circ} \mathrm{C}$. The two outputs are summed as two current sources in parallel. A level shifter contributes current to the summing junction to scale the output. The resulting current is delivered to a scaling amplifier that drives the analogto-digital (A/D) converter on the microcontroller board. The digitized signal is converted to a temperature value in degrees Celsius by the BASIC11 software's temperature-conversion subroutine. The resulting temperature value is evaluated by a temperaturecompensation subroutine to turn on/off the heater or cooling cycles of the water bath by a single-pole double-throw high-current 10-A relay and, thereby, adjust the environmental temperature to $\pm 1^{\circ} \mathrm{C}$ of that instructed by the experimental setup.

The resistance of the surface-wetness impedance sensor element changes with the amount of moisture present within the porous 
matrix of the paint coating. The sensor resistance drops from a dry value of 20 to $10 \mathrm{~K} \Omega$ as moisture collects on the sensor surface. This changing resistance modulates the current flowing through a voltage divider circuit, consisting of the sensor and a fixed $10-\mathrm{K} \Omega$ sensing resistor. The resulting current across the sensing resistor, therefore, is proportional to the current flowing through the network, which is modulated by the resistance of the moisture probe. The voltage is amplified by an operational amplifier circuit that drives the A/D converter. The digitized value is converted to percent moisture by a BASIC11 moisture-conversion subroutine.

Control of the red/infrared LED arrays is accomplished by turning on/off the desired LED array's output control bit. Each array $(660$ or $880 \mathrm{~nm}$ ) is powered by a 2N2222A BPJ (bipolar junction transistor) driver circuit. Activating an array's transistor allows current to flow to the LEDs and, thereby, turns them on. The lampcontrol subroutine of the BASIC11 program controls the transistor drivers by setting the appropriate logic levels $(+5 \mathrm{~V}$ or $0 \mathrm{~V})$ on the RTC-HC11's digital output port bits that correspond to the selected LED array.

Microprocessor control software and experimental design setup. A modular design approach was used to develop the CCEC control, for which the main menu provides the core of the program and functions performed by the software branch from the main menu to subroutines. The CCEC software, written in BASIC11, runs resident on the RTC-HC11 controller board. The user interface menus can be accessed by any standard terminal-emulation software on a desktop or portable PC. We utilized a commercial communications software package (Procomm Plus for Windows, version 2.0; Datastorm Technologies Inc., Columbia, MO) that allows asynchronous communication between the host PC and RTCHC11 microcontroller. The CCEC program's main menu provides selections for setting system time, entering environmental parameter settings (experimental design), choosing a sampling rate for data acquisition, displaying current system settings, and executing the experimental setup. From the main menu, if the environmental parameters are chosen, a submenu is produced that allows the user to select the environmental parameter to set up, i.e., RH, temperature, rain, $600-\mathrm{nm}$ red lights, $880-\mathrm{nm}$ infrared lights, or vibration. Selecting one of these parameters brings up a prompt-driven subroutine that asks for the number of events for that parameter, the setting (i.e., for RH, percent RH or for lights, on/off), and duration of the event. When all of the environmental parameters have been set, the user returns to the main menu and executes the program.

When the experiment is executed, the CCEC software takes control of the entire system. The CCEC program begins by initializing variables and a timer interrupt to signal when a user-defined sample time has arrived and scheduling experiment events. Memory is allocated for data storage in RAM. All data and time arrays are dimensioned, and user-defined experimental conditions are executed in sequence at user-selected time intervals. As the experiment progresses, the data-acquisition subroutine queries each of the environmental sensors and simultaneously displays the values for each sensor in separate columns on the PC monitor and writes the values in ASCII format to an open computer file in a userspecified directory on the PC's hard or floppy drive. When the experiment is completed, the software returns all hardware to the home default positions. The use of a communications software package such as Procomm Plus allows the user to create "script" files of experimental setups that can be reused to precisely repeat experimental conditions.

Spore-release experiments. Experiments were conducted with Mycosphaerella citri, a foliar loculoascomycete pathogen of citrus that causes greasy spot; $A$. solani, a foliar hyphomycete pathogen that causes early blight of potato and tomato; and Venturia inaequalis, the loculoascomycete that causes apple scab. For $M$. citri and $V$. inaequalis, samples consisted of naturally abscised leaves in senescing lamina in which pseudothecia of the respective fungus were imbedded and maturing. Conidia of $A$. solani were collected from stock cultures maintained on potato dextrose agar and transferred to filter papers trimmed to $5 \times 5 \mathrm{~cm}^{2}$. The filter papers were soaked for a few minutes in a solution prepared by boiling $30 \mathrm{~g}$ of tomato leaves per liter of water. The filter-paper cultures were allowed to incubate for 1 to 2 weeks at $25^{\circ} \mathrm{C}$, such that the fungal colonies covered nearly the entire paper surface, and the filter paper bearing conidial chains was placed directly in the CCEC. Experiments were conducted to test the effects of rain, shifts in RH, vibration, and light on spore release of these fungi and, thereby, test the effectiveness, operation, and stability of the CCEC.

\section{RESULTS}

The CCEC system allowed the user to reliably repeat conditions for multiple runs or comparison of isolates or species. The system was capable of responding quickly and maintaining user-defined levels for each environmental variable within acceptable tolerances. Temperature did not vary in the specimen chamber by more than $\pm 1.0^{\circ} \mathrm{C}$, and temperature probes were accurate to within $0.5^{\circ} \mathrm{C}$ when tested against a calibrated mercury thermometer. $\mathrm{RH}$ probes were generally within $2.0 \% \mathrm{RH}$ when measured against a calibrated RH meter (model RH30; Omega Engineering Inc., Stamford, $\mathrm{CT})$. High $(>85 \%)$ and low $(<30 \%) \mathrm{RH}$ were more precisely maintained at $\pm 2.5 \% \mathrm{RH}$ by the CCEC than were midrange RH values of 30 to $85 \%$, which were maintained at $\pm 18 \% \mathrm{RH}$. The hysteresis in $\mathrm{RH}$, especially at midrange values, was unavoidable due to the feedback control between the two solid-state RH sensors and the stepper motor controlling the mixer valve, which caused continual correction to $\mathrm{RH}$ during an experiment. Because of the reaction time of the RH sensors $(\approx 2 \mathrm{~min})$, the $\mathrm{RH}$ level exceeded or dropped below the user-defined value before the system could compensate. This was damped somewhat by incorporating an algorithm in the stepper motor control subroutine that anticipated potential overshooting during user-specified changes in RH. In addition, RH sensor sensitivity was less accurate at $\mathrm{RH}<20 \%$ and $>85 \%$, which is an inherent problem with all RH measurements. Sensor wetness was accurately recorded when it occurred, and leaf-wetness values between dry and saturated corresponded well to visual drying of the specimen, as viewed through the Plexiglas window in the side of the environmental chamber.

Rain events could be scheduled and executed precisely for a predetermined duration and were adjustable within the range of 138 to $264( \pm 10) \mathrm{ml} \mathrm{min}^{-1}$. To avoid flooding the specimen chamber, individual rains were restricted to $30 \mathrm{~s} \mathrm{~min}^{-1}$ but could be repeated indefinitely to simulate continuous rain events. Average raindrop volume was measured volumetrically as $0.027 \mathrm{ml}$ by catching 50 drops and calculating the average volume. The diameter of a $0.027-\mathrm{ml}$ raindrop was calculated by the equation for the diameter of a sphere known to have a volume of $0.37 \mathrm{~cm}$. The diameter of natural raindrops ranges from 0.2 to $5.0 \mathrm{~mm}$ (23). Using equations 2 through 5 from Madden (23) and Reynolds et al. (27), the terminal velocity of a $0.37-\mathrm{cm}$-diameter water drop that falls $0.7 \mathrm{~m}$ was calculated to be $0.156 \mathrm{~m} \mathrm{~s}^{-1}$. The calculated energy potential of single raindrops striking the specimen from a height of $69.8 \mathrm{~cm}$ was $\approx 0.33 \mu \mathrm{J}(1 / 2 \times$ mass $\times$ velocity $=0.5[2.7 \times$ 10 to $\left.5 \mathrm{~kg}]\left[4.62 \mathrm{~m}^{-2} \mathrm{~s}^{-2}\right]=3.277 \times 10^{-7} \mathrm{~kg} \mathrm{~m}^{-2} \mathrm{~s}^{-2}=0.33 \mu \mathrm{J}\right)$. Because $0.7 \mathrm{~m}$ is less than the distance needed for simulated raindrops to achieve terminal velocity, the simulated raindrops generated by the CCEC had less energy potential than natural raindrops, for which terminal velocity or even greater velocity might be achieved, depending on up and down drafts. By removing the screen in the rain tower, a gentle mist also could be produced from which very small atomized droplets accumulated on the specimen with very little vibration from the impact of falling droplets.

Environmental data acquired from the data-acquisition subroutine were imported directly into a spreadsheet program and easily correlated with spore catches estimated by microscope readings of 
the spore-trap tape. The data were entered into a spreadsheet program for further processing and eventually imported into graphics software programs for preparation of graphs as presented here (Figs. 2 through 6).

Figure 2 is used as an illustration of the experimental parameter settings and the resulting environmental conditions measured within the specimen chamber. The experimental setup was as follows: $\mathrm{RH}=50 \%$ for 0 to $110 \mathrm{~min}, 20 \%$ for 110 to $130 \mathrm{~min}$, and $95 \%$ for 130 to $190 \mathrm{~min}$; temperature $=24^{\circ} \mathrm{C}$ constant; red/infrared radiation $=$ on at 50,70 , and $90 \mathrm{~min}$ for $2 \mathrm{~min}$ each; vibration $=$ momentary at 10, 20, and $30 \mathrm{~min}$; and rain = on at 150 and $170 \mathrm{~min}$ for $1 \mathrm{~min}$ each. The chamber was wetted prior placement of the specimen in it. RH was maintained between 45 and $62 \%$ for 0 to $120 \mathrm{~min}$. RH began dropping, as requested, at $110 \mathrm{~min}$ toward the

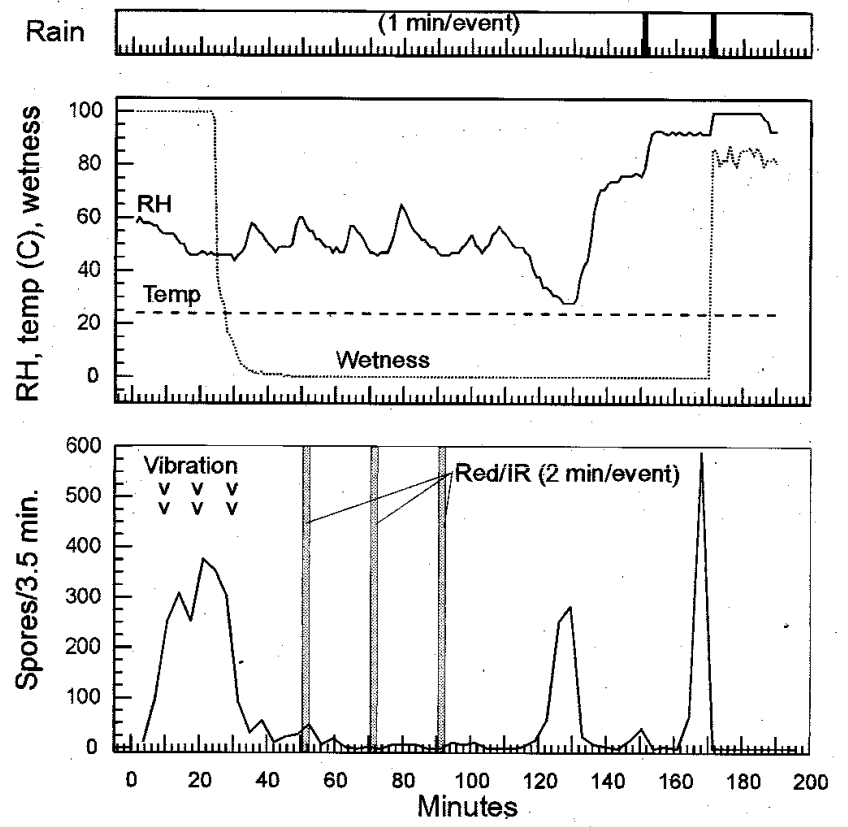

Fig. 2. Conidia release by Alternaria solani in response to decreasing relative humidity $(\mathrm{RH})$, vibration (three events, indicated by v), red/infrared (Red/ IR) radiation (three events for $30 \mathrm{~s}$ each, indicated by vertical gray bars), and rain (two events for $60 \mathrm{~s}$ each) at relatively constant temperature.

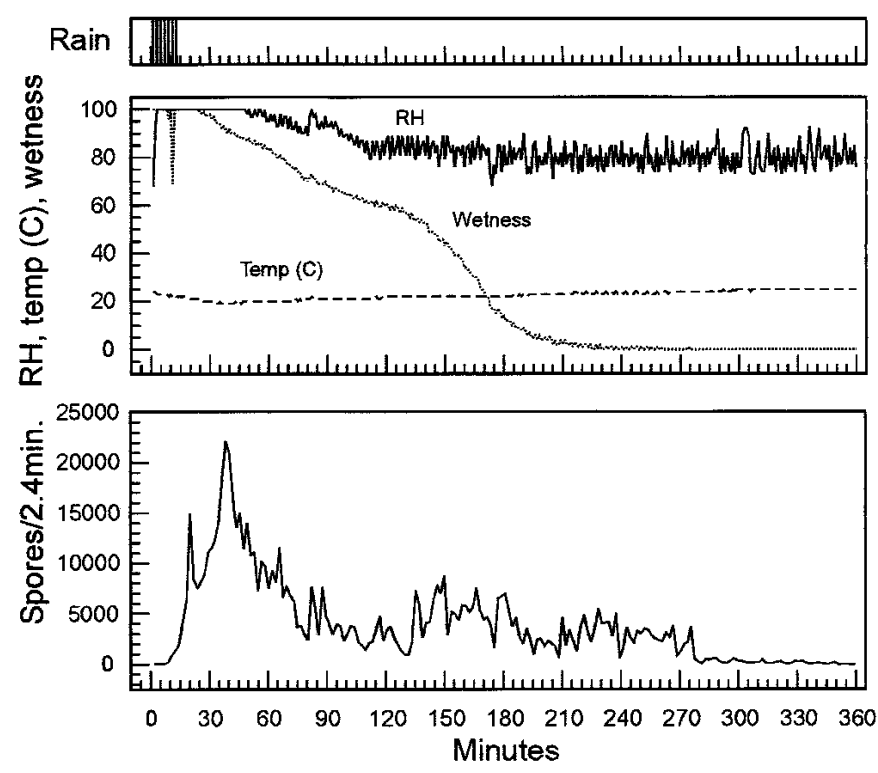

Fig. 3. Ascospore discharge of Mycosphaerella citri in response to a single 15-min rain event at relatively constant temperature and relative humidity $(\mathrm{RH})$. requested $20 \% \mathrm{RH}$, reaching $27 \%$ prior to the next request for $95 \% \mathrm{RH}$ at $130 \mathrm{~min}$. At $130 \mathrm{~min}$, the $\mathrm{RH}$ began to rise rapidly and achieved $79 \%$ prior to the first rain event. The requested rain event at 150 min immediately brought the RH to the desired $95 \%$, which was maintained $( \pm 2 \% \mathrm{RH})$ until the second rain event, which raised the RH to $100 \%$. The $100 \%$ RH was held until 185 min, when sufficient drying had occurred to allow the RH to achieve the $95 \% \mathrm{RH}$ requested. Temperature was held at $24^{\circ} \mathrm{C}$ for the duration of the experiment, as requested. Light, vibration, and rain events were executed and terminated precisely at the times requested. Wetness was not controlled but merely measured and demonstrated the drying of the initially wet chamber and instantaneous wetting due to the second rain event. The wetness sensor was located directly below the specimen and did not react to the first rain event, because the first rain event wetted the specimen

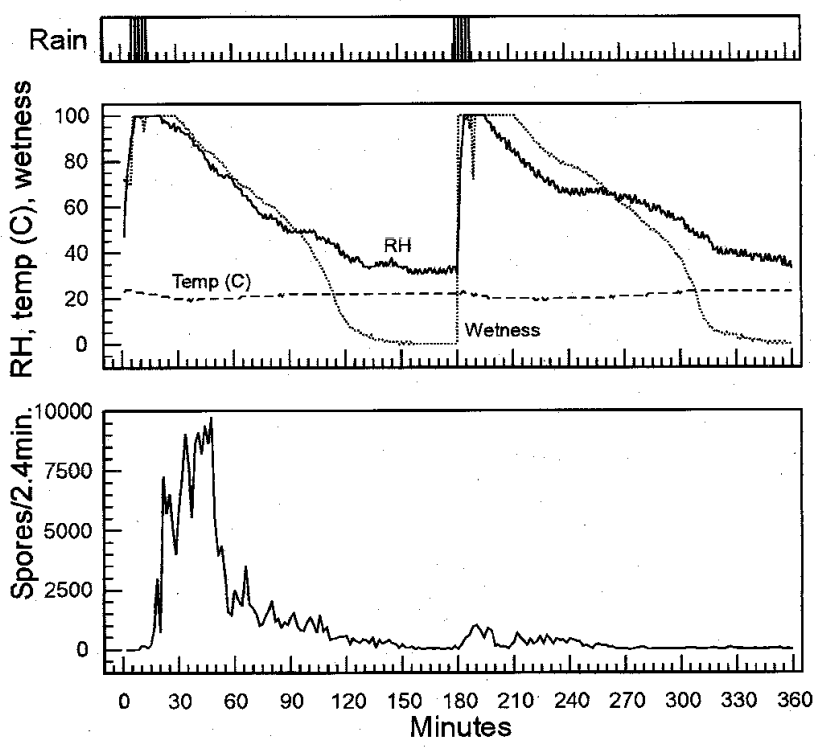

Fig. 4. Ascospore discharge of Mycosphaerella citri in response to two rain events, $10 \mathrm{~min}$ each, separated by $180 \mathrm{~min}$ of no rain at relatively constant temperature and relative humidity $(\mathrm{RH})$. The major peak of ascospore discharge after the first rain event and the much diminished minor peak after the second rain event indicate an exhaustion of mature pseudothecia.

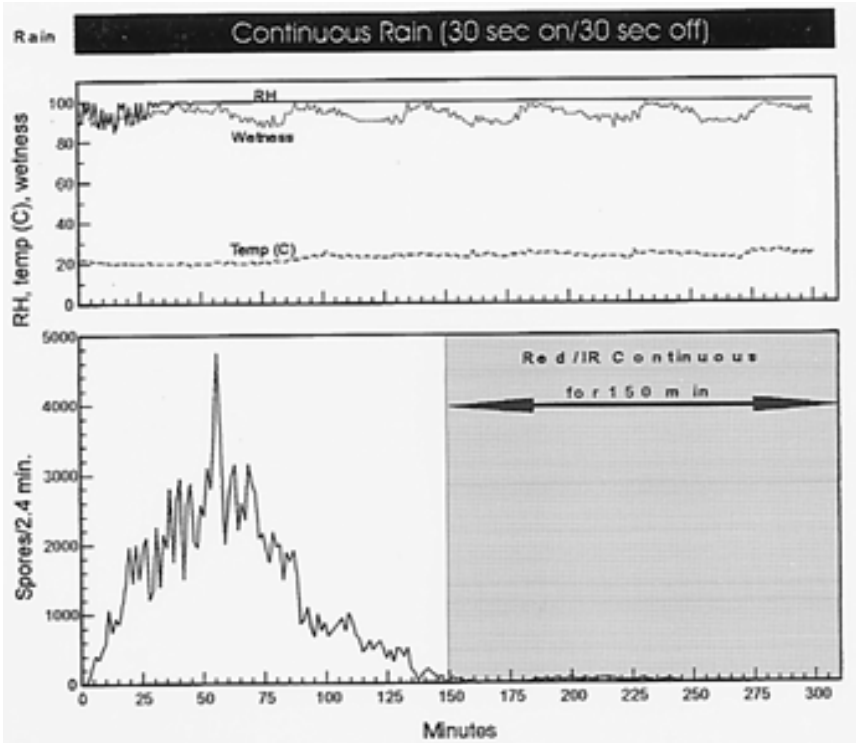

Fig. 5. Ascospore discharge of Venturia inaequalis in response to continuous rain at relatively constant temperature. Rain events (30 s on, $30 \mathrm{~s}$ off) were continuous for the duration of the experiment. Specimen was subjected to red/ infrared (Red/IR) radiation after $150 \mathrm{~min}$. 
but sufficient rain did not collect on the specimen to allow it to drip onto the wetness sensor until the second rain event. RH was the most difficult parameter to control. Although RH began to change immediately upon request, a few minutes often was required to achieve the new requested RH level. Requested changes for decreasing RH were slower to occur than for increasing RH, indicating that it was easier to add moisture to the specimen chamber and more difficult to remove it, especially if the chamber had free moisture in the bottom or on the walls after a rain event or condensation.

Spore release/discharge was achieved for all of the fungal plant pathogens tested. Conidia release was achieved for the hyphomycete $A$. solani in response to changes in RH (decrease from 50 to $30 \% \mathrm{RH}$ at 110 to $130 \mathrm{~min}$ ), vibration (at 10,20 , and $30 \mathrm{~min}$ ), and rain (two events of $1 \mathrm{~min}$ each at 150 to 151 and 170 to $171 \mathrm{~min}$ ) but not red/infrared radiation (three events of $2 \mathrm{~min}$ each at 50 to 52,70 to 72 , and 90 to $92 \mathrm{~min}$ ). In addition, A. solani responded to rain showers by producing peaks of conidiospore release, demonstrating the importance of this environmental variable as well (Fig. 2).

Ascospore discharge for both ascomycete species studied was observed primarily in response to rain events. For $M$. citri, ascospore discharge began a few minutes after a rain event of $15 \mathrm{~min}$, then continued but diminished as the specimen of decomposing leaves was allowed to dry over a 3-h period (Fig. 3). Multiple rain events demonstrated that the $M$. citri pseudothecia were nearly exhausted after the first rain event (Fig. 4). For the apple scab fungus, $V$. inaequalis, continuous rain (cycles of $30 \mathrm{~s}$ on followed by $30 \mathrm{~s}$ off) caused ascospore discharge within $5 \mathrm{~min}$ of rain initiation. Maximum ascospore discharge occurred after $\approx 55 \mathrm{~min}$ of rain and diminished to nondetectable levels after $250 \mathrm{~min}$ of rain. Subjecting the specimen to red/infrared radiation after $150 \mathrm{~min}$ did not stimulate additional discharge (Fig. 5). However, intermittent rain showers of 1 min spaced $20 \mathrm{~min}$ apart tended to stimulate peaks of ascospore discharge in response to each rain event (Fig. 6), but lower ascospore numbers were recovered com-

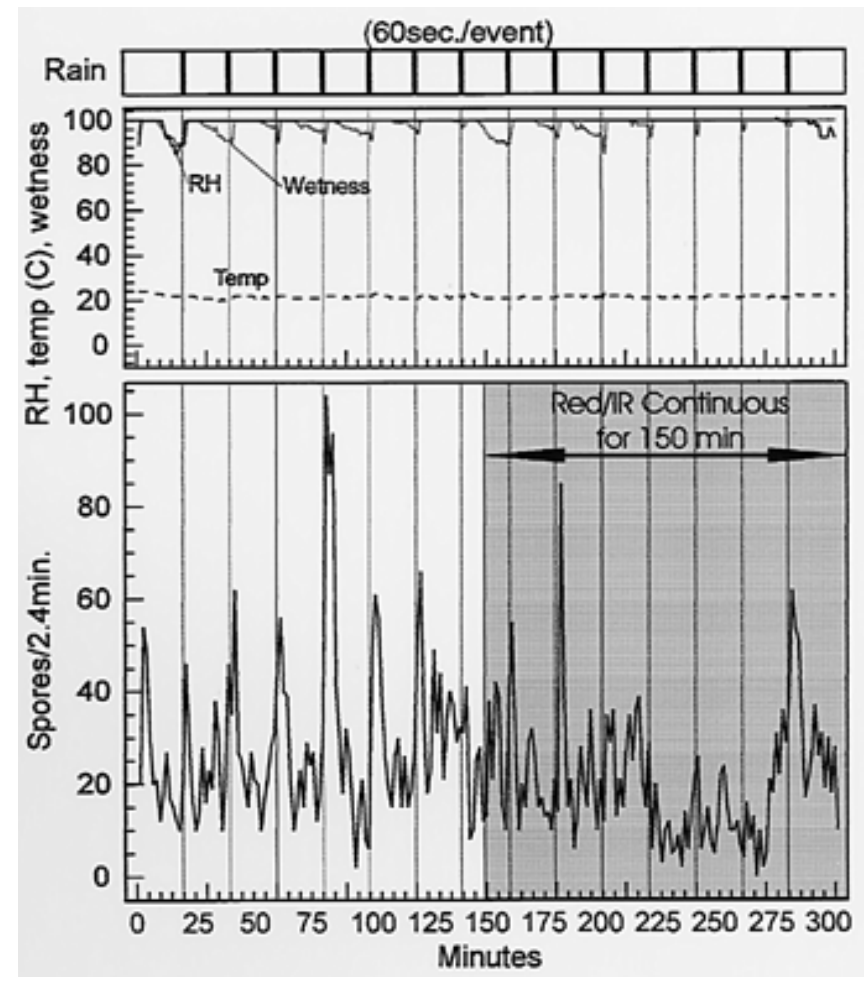

Fig. 6. Ascospore discharge of Venturia inaequalis in response to multiple 1-min rain events spaced 19 min apart at relatively constant temperature. Ascospore discharge peaked after each associated rain event. Specimen was subjected to red/infrared (Red/IR) radiation after $150 \mathrm{~min}$. pared to a continuous rain event (compare with Fig. 5). No difference in discharge intensity was seen when the specimen was subjected to red/infrared radiation after $150 \mathrm{~min}$. These results are meant as examples of the function and capabilities of the CCEC and not as exhaustive evidence of the definitive relationships between environmental variables and spore release of these fungi.

\section{DISCUSSION}

The CCEC described in this article was developed to study spore release from fungal plant pathogens in much the same way as previous noncomputerized devices have been (18). However, the computer control of the CCEC described here allows precision and repeatability of experimental designs involving complex environmental changes. In addition, experiments need not be attended, and experiments lasting many hours may be conducted without the need for user input or adjustment. Computerized data acquisition also simplifies data collection compared to other devices that require transcription of strip-chart recordings of environmental parameters and periodic manual readings of other parameters.

Environmental variables that previously have been shown to stimulate fungal spore release worked as expected and as previously described for shifts in $\mathrm{RH}$, effects of rain and drying, effects of red and infrared radiation, and effects of vibration, validating the ability and reliability of this device for studying spore release $(8-10,17,18,20,21)$. The use of solid-state, capacitive $\mathrm{RH}$ sensors improved the response time and repeatability of RH measurements, and the sensors had similar accuracy compared to previous wet/dry bulb thermocouple comparisons (18). Shifts in RH elicited conidia release by $A$. solani, which is consistent with the spore release demonstrated for other hyphomycetes with previous devices $(8-10,17,18,20,21)$. The use of narrow-wavelength, highintensity LEDs for generation of red and infrared radiation narrowed the spectral spread and eliminated the heat generated by incandescent lights. The CCEC also incorporates a rain tower to simulate rain showers of variable duration, which differs from previous devices (18) but is similar to a recently published device for the study of spore release by $V$. inaequalis (6). The immediate and long-term effects of rain showers on spore release were demonstrated for all three fungi tested and, although the experimental parameters differed, confirmed the findings for rain-shower stimulation of ascospore release by $V$. inaequalis and $V$. pirina $(3,4,16$, 22,29).

\section{ACKNOWLEDGMENTS}

We thank B. K. Smith for partial software development, S. M. Richie for consultation on electronics, T. D. Riley for technical assistance, and D. Gadoury for providing $V$. inaequalis specimens and advice.

\section{LITERATURE CITED}

1. Adams, G. C., Jr., Gottwald, T. R., and Leach, C. M. 1986. Environmental factors initiating liberation of conidia of powdery mildews. Phytopathology 76:1239-1245.

2. Aylor, D. E. 1978. Dispersal in time and space: Aerial pathogens. Pages 159-180 in: Plant Disease: An Advanced Treatise. Vol 2. J. G. Horsfall and E. B. Cowling, eds. Academic Press, New York.

3. Aylor, D. E., and Sutton, T. B. 1992. Release of Venturia inaequalis ascospores during unsteady rain: Relationship to spore transport and deposition. Phytopathology 82:532-540.

4. Brook, P. J. 1969. Effect of light, temperature, and moisture on release of ascospores by Venturia inaequalis (Cke.) Wint. N.Z. J. Agric. Res. 12: 214-227.

5. Fitt, B. D. L., and McCartney, H. A. 1986. Spore dispersal in splash drop lets. Pages 87-104 in: Water, Fungi and Plants. P. G. Ayers and L. Boddy, eds. Cambridge University Press, Cambridge.

6. Gadoury, D. M., Stensvand, A., and Seem, R. C. 1996. A wind tunnel for controlled-environmental studies of ascospore release by Venturia inae qualis. Phytopathology 86:596-601. 
7. Gillespie, T. J., and Kidd, G. E. 1978. Sensing duration of leaf moisture retention using electrical impedance grids. Can. J. Plant Sci. 58:179-187.

8. Gottwald, T. R. 1982. Spore discharge by the pecan scab pathogen, Cladosporium caryigenum. Phytopathology 72:1193-1197.

9. Gottwald, T. R. 1983. Factors affecting spore liberation by Cladosporium carpophilum. Phytopathology 73:1500-1505.

10. Gottwald, T. R., and Tedders, W. R. 1982. Studies on conidia release by the entomogenous fungi Bavaria bassiana and Metarhizium anisopliae (Deuteromycotina: Hypomycetes) from adult pecan weevil (Coleoptera: Curculionidae) cadavers. Environ. Entomol. 11:1274-1279.

11. Gregory, P. H., Guthrei, E. J., and Bunce, M. E. 1995. Experiments on splash dispersal of fungal spores. J. Gen. Microbiol. 20:328-354.

12. Hammett, K. R. W., and Manners, J. G. 1971. Conidium liberation in Erysiphae graminis. I. Visual and statistical analysis of spore trap records. Trans. Br. Mycol. Soc. 56:387-401.

13. Harvey, R. 1967. Air spore studies at Cardiff. I. Cladosporium. Trans. Br. Mycol. Soc. 50:479-495.

14. Hirst, J. M. 1953. Changes in atmospheric spore content: Diurnal periodicity and the effect of weather. Trans. Br. Mycol. Soc. 36:375-393.

15. Ingold, C. T. 1971. Fungal spores, their liberation and dispersal. Clarendon Press, Oxford.

16. Latorre, B. A., Yañez, P., and Rauld, E. 1985. Factors affecting release of ascospores by the pear scab fungus (Venturia pirinia). Plant Dis. 69:213216.

17. Leach, C. M. 1975. Influence of humidity and red-infrared radiation on violent spore release by Drechslera turcica and other fungi. Phytopathology 65:1303-1312.

18. Leach, C. M. 1980. An apparatus for precise control of humidity, temperature, airflow, and light in spore discharge studies. Phytopathology
70:189-191.

19. Leach, C. M. 1980. Influence of humidity and red-infrared radiation on spore discharge by Drechslera turcica-Additional evidence. Phytopathology 70:192-196.

20. Leach, C. M. 1980. Influence of humidity, red-infrared radiation, and vibrational spore discharge by Pyricularia oryzae. Phytopathology 70:201-205.

21. Leach, C. M. 1982. Active sporangium discharge of Peronospora destructor. Phytopathology 72:881-885.

22. MacHardy, W. E., and Gadoury, D. M. 1986. Patterns of ascospore discharge by Venturia inaequalis. Phytopathology 76:985-990.

23. Madden, L. V. 1992. Rainfall and dispersal of fungal spores. Pages 39-79 in: Advances in Plant Pathology. Vol. 8. Academic Press, New York.

24. Madden, L. V., Ellis, M. A., Grove, G. G., Reynolds, K. M., and Wilson, L. L. 1991. Epidemiology and control of leather rot of strawberries. Plant Dis. 75:439-446.

25. Meredith, D. S. 1973. Significance of spore release and dispersal mechanisms in plant disease epidemiology. Annu. Rev. Phytopathol. 11:313341.

26. Pady, S. M., Kramer, C. L., and Clary, R. 1969. Periodicity in spore release in Cladosporium. Mycologia 61:87-98.

27. Reynolds, K. M., Madden, L. V., Reichard, D. L., and Ellis, M. A. 1987. Methods for study of raindrop impact on plant surfaces with application to predicting inoculum dispersal by rain. Phytopathology 77:226-232.

28. Reynolds, K. M., Madden, L. V., Reichard, D. L., and Ellis, M. A. 1989. Splash dispersal of Phytophthora cactorum from infected strawberry fruit by simulated canopy drip. Phytopathology 79:425-432.

29. Spotts, R. A., and Cervantes, L. A. 1993. Factors affecting maturation and release of ascospores of Venturia pirina in Oregon. Phytopathology 84:260-264. 